Artículo científico

Volumen 32(2):587-598. Mayo-agosto, 2021

e-ISSN 2215-3608, doi:10.15517/am.v32i2.43179

https://www.revistas.ucr.ac.cr/index.php/agromeso

\title{
Detección de IHHNV en el cultivo de Litopenaeus vannamei en Costa Rica ${ }^{1}$
}

\section{Detection of IHHNV in Litopenaeus vannamei farms in Costa Rica}

\author{
Jose Francisco Parajeles-Mora², Nelson Peña-Navarro ${ }^{3}$,Antony Solorzano-Morales ${ }^{2}$, Gaby Dolz ${ }^{2}$
}

1 Recepción: 29 de julio, 2020. Aceptación: 10 de diciembre, 2020. Este trabajo formó parte del trabajo de graduación de Jose Francisco Parajeles-Mora, para optar al grado de Licenciatura en Medicina Veterinaria de la Universidad Nacional (UNA) de Costa Rica y fue financiado mediante el Fondo Institucional de Desarrollo Académico (FIDA).

2 Universidad Nacional, Escuela de Medicina Veterinaria, Laboratorio de Investigación en Medicina Poblacional, P.O. Box 86-3000, Heredia, Costa Rica.jfparajeles@gmail.com (https://orcid.org/0000-0003-3658-2877), antony.solorzano.morales@una.ac.cr (https://orcid.org/00000001-7774-8306), gaby.dolz.wiedner@una.ac.cr (https://orcid.org/0000000295665130, autor para la correspondencia).

3 Universidad Técnica Nacional, Dirección de Investigación, Sede del Pacífico, Puntarenas, Costa Rica.npena@utn.ac.cr (https://orcid. org/000000028916812X).

\section{Resumen}

Introducción. El virus de la necrosis hipodérmica y hematopoyética infecciosa (IHHNV) produce deformidades cuticulares y reducción del crecimiento del camarón blanco (Litopenaeus vannamei), lo que genera pérdidas productivas por un menor peso de cosecha y menores precios de mercado. Aunque se han descrito linajes patógenos y no patógenos del agente, se desconoce si estos están presentes en el país. Objetivo. Caracterizar los linajes de IHHNV presentes en fincas de camarón blanco en Costa Rica. Materiales y métodos. Entre 2017 y 2018 se investigaron quince granjas camaroneras distribuidas en el Golfo de Nicoya, Guanacaste, Costa Rica. En estas fincas se recolectaron muestras de agua, postlarvas y camarones juveniles, durante un ciclo de producción de tres meses, se tomaron los parámetros fisicoquímicos del agua de los estanques y se aplicó una encuesta a los productores para conocer si tenían conocimiento sobre la enfermedad y si sospechaban de la presencia del agente en sus establecimientos. Las muestras recolectadas se analizaron mediante Reacción en Cadena de Polimerasa (PCR) y secuenciación. Resultados. La presencia de IHHNV se determinó en el 86,6 \% (13/15) de las fincas analizadas, la secuenciación de los productos amplificados estableció la presencia del linaje III de IHHNV, con un 99,2 \%-100,0 \% (386-389/389 pb) de similitud con la secuencia aislada en L. vannamei de Venezuela (KM485615.1). Los parámetros fisicoquímicos del agua se determinaron como deficientes. Un 53,3\% de productores no tenían conocimiento de IHHNV, mientras que los restantes sospechaban tener el agente en su finca. Conclusión. El linaje patógeno III de IHHNV estuvo presente en la mayoría de las fincas. Se recomienda capacitar a los productores y establecer protocolos de bienestar, manejo y bioseguridad para así mejorar los parámetros productivos de sus fincas.

Palabras clave: enfermedad infecciosa, genotipaje, linajes patógenos.

\begin{abstract}
Introduction. The infectious hypodermal and haematopoietic necrosis virus (IHHNV) produces cuticular deformities and growth reduction of white shrimp (Litopenaeus vannamei) causing losses due to a lower harvest
\end{abstract}


weight and lower market prices. Although different pathogenic and non-pathogenic genotypes of IHHNV have been described, it is unknown whether these are present in the country. Objective. To characterize the IHHNV lineages present in white shrimp farms in Costa Rica. Materials and methods. Between 2017 and 2018, a total of 15 shrimp farms distributed in the Gulf of Nicoya, Guanacaste, Costa Rica were investigated. Water, postlarvae, and juvenile shrimp samples were collected during a production cycle of three months, additionally, physicochemical parameters of the water in the ponds were measured and a survey was applied to the producers, to know if they had knowledge about the disease and if they suspected the presence of the agent in their establishments. The collected samples were analyzed by Polymerase Chain Reaction (PCR) and sequencing. Results. The presence of IHHNV was determined in $86.6 \%$ $(13 / 15)$ of the farms analyzed, the sequencing of the amplified products determined the presence of IHHNV lineage III, with $99.2 \%-100.0 \%$ (386-389/389 bp) similarity with the sequence isolated from L. vannamei in Venezuela (KM485615.1). Poor physicochemical parameters of the water were determined. A total of $53.3 \%$ of producers had not heard of IHHNV, while the remaining producers suspected having the virus on their farms. Conclusion. IHHNV pathogenic lineage III was present in most of the farms. It is recommended to train producers and establish welfare, management, and biosecurity protocols in order to improve the productive parameters of their farms.

Keywords: infectious disease, genotyping, pathogenic lineages.

\section{Introducción}

El virus de la necrosis hipodérmica y hematopoyética infecciosa (IHHNV, por sus siglas en inglés) fue descubierto en Hawái en 1981, año en el cual provocó la mortalidad de aproximadamente el 90 \% de los camarones Litopenaeus stylirostris cultivados en esa isla (Robles-Sikisaka et al., 2010). Desde entonces el virus se ha detectado en otras especies de la familia de los peneidos alrededor del mundo (Tang \& Lightner, 2002). El virus pertenece a la familia Parvoviridae, género Penstyldensovirus, un virus no envuelto, altamente resistente en el ambiente, con un genoma de ADN de una sola cadena de 4,1 kb (Shike et al., 2000). El genoma de IHHNV se ha logrado secuenciar casi por completo y se describen tres linajes patógenos, el linaje I encontrado en Australia, el linaje II en el Sur de Asia y el linaje III en América y Este de Asia (principalmente Filipinas). Adicionalmente, existen otras dos secuencias (A y B) que se encuentran incorporadas en el genoma de los peneidos y no son infecciosas para las especies hospederas, las cuales fueron reportadas en Madagascar (A), Australia (B) y Tanzania (B) (Silva et al., 2014).

La transmisión horizontal ocurre por ingesta de camarones muertos infectados (canibalismo) o por contacto con agua que contenga animales infectados, así como por vectores como las aves (Vanpatten et al., 2004). La transmisión vertical ocurre cuando la madre lo transmite a la descendencia, ya sea por contacto con partículas virales liberadas durante el desove e ingeridas por las larvas durante la primera alimentación, o bien por la transmisión directa a los oocitos (Cuéllar-Anjel, 2013). Los huevos de hembras infectadas con el IHHNV, generalmente no llegan a desarrollarse ni a eclosionar, pero aquellos que eclosionan muestran una alta prevalencia de infección, por lo que los animales que sobreviven pueden portar el virus de por vida y pasarlo a la progenie y a otras poblaciones, tanto por transmisión vertical como horizontal (Montgomery-Brock et al., 2007).

Los linajes patógenos de IHHNV, actualmente no ocasionan altas tasas de mortalidad en L. vannamei, sin embargo, provocan una enfermedad conocida como síndrome de la deformidad y del enanismo, que se caracteriza por un crecimiento reducido e irregular con deformidades cuticulares en el rostrum y los apéndices anteriores, que se refleja en una reducción de un 10 a un 50 \% del crecimiento (Kalagayan et al., 1991); provocando, por consiguiente, una gran variación en el peso de la cosecha final, menor precio de mercado y, por ende, pérdidas económicas sustanciales (Organización Mundial de Sanidad Animal [OIE], 2015). 
No existen estudios en Costa Rica que hayan cumplido con los requisitos que solicita la Organización Mundial de Sanidad Animal (OIE) para confirmar un caso positivo de IHHNV, que consiste en diagnosticar la presencia del agente mediante dos de tres técnicas que se enumeran a continuación: 1. Hibridación in situ, 2. Reacción en Cadena de la Polimerasa (PCR) linaje patógeno específico (309 pb-PCR), 3. Secuenciación. Tampoco se han determinado los linajes de IHHNV presentes en el país (OIE, 2019). El único trabajo que reportó la presencia de IHHNV en Costa Rica, se realizó en una finca y se diagnosticó mediante histopatología y un PCR, que detecta todos los linajes del virus (patógenos y no patógenos, 389 pb-PCR), lo que constituye un reporte de caso sospechoso de IHHNV de acuerdo con la OIE (Peña-Navarro \& Varela-Mejías, 2016). El objetivo de este trabajo fue determinar los linajes de IHHNV presentes en fincas de cultivo de camarón blanco de Costa Rica.

\section{Materiales y métodos}

\section{Tipo de estudio y recolecta de muestras}

Entre enero 2017 y junio 2018 se realizó un estudio no sistemático y por conveniencia, transversal y descriptivo. De un total de 89 fincas productoras de camarón blanco (Litopenaeus vannamei), activas a nivel nacional (Dra. Carolina Elizondo, SENASA, comunicación personal, 2019), se escogieron quince fincas que cumplieran con los siguientes criterios de inclusión: 1. Fincas poco tecnificadas, 2. Un estanque de producción y 3. Mortalidad de camarones, ya que se presumió que eran las fincas en las que habría más posibilidad de encontrar IHHNV. Las fincas se ubicaron alrededor del Golfo de Nicoya de Costa Rica.

Durante el proceso de llenado del estanque, previo a la siembra, se tomó una muestra de $10 \mathrm{ml}$ de agua, además, se recolectó alrededor de cien postlarvas en proceso de acondicionamiento. Después de siete semanas de realizada la siembra, se visitaron otra vez las fincas y se tomaron diez camarones en tres diferentes sitios (a la entrada del agua, en el medio y en el sitio de desagüe del estanque). A estos animales se les extrajo el hepatopáncreas y el estómago, los cuales se almacenaron en alcohol al $95 \%$ y se congelaron a $-80{ }^{\circ} \mathrm{C}$, hasta su procesamiento.

\section{Toma de parámetros fisicoquímicos del agua, coordenadas geográficas y datos de manejo}

Al momento de obtener las muestras juveniles de camarón, se tomaron los parámetros fisicoquímicos de la calidad del agua (temperatura, oxígeno, $\mathrm{pH}$ y salinidad) con un multiparámetro portátil (Hanna ${ }^{\circledR}$ Instruments, USA). Se registraron las coordenadas geográficas de las cuatro esquinas de cada uno de los estanques en los que se recolectaron los camarones juveniles, con un equipo de posicionamiento global (GPS Garmin, USA). A los productores de las fincas participantes se les aplicó una encuesta para conocer si sabían sobre IHHNV o si sospechaban de su presencia en las camaroneras.

\section{PCR, secuenciación y análisis filogenia}

Las muestras se sometieron a un lavado con fenol-cloroformo-alcoholisoamílico (50:48:2), posteriormente se procedió a realizar la extracción de ADN genómico y viral utilizando el kit Dneasy® Blood and Tissue, (QIAGEN, Venlo, Netherlands), con base en las instrucciones del fabricante. Las concentraciones de ADN de las muestras extraídas se determinaron con Nanodrop. Las muestras se sometieron inicialmente a un PCR para amplificar una secuencia parcial del gen $\beta$-actina (Dhar et al., 2001) y descartar inhibiciones en la amplificación de las muestras. Se utilizaron los iniciadores Actin-F (5'-CCCAGAGCAAGAGGTA-3') y Actin-R3 (5'GCGTATCCTTCGTAGATGGG-3'). El volumen de la reacción (25 $\mu 1$ l) incluyó 12,5 $\mu 1$ de Dream TaqTM PCR Master Mix 2X (Thermo Scientific, Waltham, USA), 0,75 $\mu 1$ de cada iniciador a una concentración de 10 pmol/ 
$\mu 1^{-1}, 1,5 \mu 1$ de ADN y 9,5 $\mu 1$ de agua grado biología molecular (Thermo Scientific). Los pasos de ciclaje térmico consistieron en: 2 min. de desnaturalización inicial a $94{ }^{\circ} \mathrm{C}, 35$ ciclos repetidos de desnaturalización $\left(94{ }^{\circ} \mathrm{C}\right.$ por $20 \mathrm{~s}$ ), alineación $\left(55^{\circ} \mathrm{C}\right.$ por $\left.10 \mathrm{~s}\right)$, extensión $\left(72{ }^{\circ} \mathrm{C}\right.$ por $\left.30 \mathrm{~s}\right)$ y una extensión final a $72{ }^{\circ} \mathrm{C}$ por 5 min. El tamaño del fragmento amplificado fue de $339 \mathrm{pb}$, el cual se visualizó mediante electroforesis en gel de agarosa al $1 \%$ en amortiguador TBE 0.5x (Tris Base, Ácido bórico, EDTA pH 8, 0,5 M), teñidos con Gel Red $\left(0,5 \mu \mathrm{g} \mathrm{ml}^{-1}\right)$ y corridos en una cámara de electroforesis a 100 voltios durante $45 \mathrm{~min}$. Como marcador de peso molecular se utilizó GeneRuler 100 bp DNA Ladder Plus (ThermoScientific, Waltham, USA).

Las muestras se sometieron al análisis molecular de secuencias de la región codificante para una porción de la proteína no-estructural (ORF1) de IHHNV, mediante un PCR (389 pb-PCR) que detecta todas las variantes genéticas de IHHNV (Tang et al., 2007). Se utilizaron los iniciadores 389F (5'-CGGAACACAACCCGACTTTA-3') y 389R (5'-GGCCAAGACCAAAATACGAA-3') (OIE, 2017). Se utilizó el mismo protocolo descrito para el PCR del gen de actina, únicamente se aumentó el tiempo de la extensión final a cinco minutos. El tamaño del fragmento amplificado fue de $389 \mathrm{pb}$, el cual se visualizó mediante electroforesis del mismo modo anteriormente mencionado. Los productos del 389 pb-PCR fueron enviados a Macrogen (Seoul, Korea), para su purificación y secuenciación. Las secuencias parciales se alinearon con el programa Bio Edit Sequence Aligment Editor ${ }^{\circledR}$ (Hall, 1999) y se compararon mediante el algoritmo BLASTn con secuencias de la base de datos del NCBI (Nacional Center for Biotechnology Information). Luego se importaron en MEGA X (Kumar et al., 2018), para el diseño del cladograma. Se calcularon diez mil réplicas (Felsenstein, 1985). Se utilizaron como referencia las secuencias DQ228358.1 (Madagascar) y EU675312.1 (Australia) para la secuencia tipo A, AY124937.1 (Tanzania) para la secuencia tipo B, CQ475529.1 (Australia) para el linaje I, AY362547.1 (Tailandia) para el linaje II y KM485615.1 (Venezuela) para el linaje III.

Las muestras que arrojaron resultados positivos en el 389 pb-PCR se sometieron al análisis molecular de secuencias de una región codificante más pequeña de la proteína no-estructural (ORF1) de IHHNV, mediante un PCR (309 pb-PCR), que detecta solo los linajes patógenos de IHHNV (Cowley et al., 2018). Se utilizaron los iniciadores 309F (5'-TCCAACACTTAGTCAAAACCAA-3') y 309-R (5'-TGTCTGCTACGATGATTATCCA-3') (OIE, 2017). Se utilizó el mismo protocolo de PCR descrito anteriormente para los iniciadores $389 \mathrm{~F} / \mathrm{R}$, únicamente ampliando el tiempo de extensión final a siete minutos. Los fragmentos amplificados se visualizaron mediante electroforesis como se describió anteriormente. Segmentos de tamaño 309 pb se enviaron a Macrogen para su purificación y secuenciación. Se realizó alineación de la secuencia parcial y se creó el cladograma en MEGA X utilizando las mismas secuencias de referencia descritas arriba.

\section{Análisis de datos}

Se procedió a crear una base de datos en la que se incluyó el sitio de muestreo, fecha de toma de muestras, coordenadas geográficas, parámetros fisicoquímicos del agua, respuestas de las encuestas y los resultados de los 389 pb-PCR y 309 pb-PCR. Mediante la utilización del programa QGIS 2.14.0, se creó un mapa para mostrar la distribución de las fincas camaroneras analizadas y los casos positivos identificados.

\section{Resultados}

Los resultados del análisis de las diferentes muestras recolectadas en las fincas mediante los dos PCR para IHHNV se muestran en el Cuadro 1. Las dos pruebas moleculares utilizadas concordaron en un total de 113 muestras (94,1 \% concordancia), resultando más sensible el 389 pb-PCR, que logró amplificar secuencias de 
IHHNV en siete muestras adicionales (Cuadro 1). Un total de trece $(86,7 \%)$ fincas resultaron positivas a IHHNV, en dos fincas se determinó la presencia IHHNV tanto en las muestras de agua, como en postlarvas, estómagos y hepatopáncreas de los camarones juveniles recolectados al inicio, mitad y final del estanque (Cuadro 1). Todas las muestras amplificaron para el gen $\beta$-actina, descartando inhibiciones.

Cuadro 1. Resultado del análisis de las muestras de agua, postlarvas, estómagos y hepatopáncreas de los camarones juveniles (Litopenaeus vannamei), mediante 389 pb-PCR y 309 pb-PCR para la detección del virus de la necrosis hipodérmica y hematopoyética infecciosa (IHHNV) en 15 fincas del Golfo de Nicoya y el Pacífico Central de Costa Rica, durante el periodo 2017-2018.

Table 1. Results of the PCR analysis IHHNV of water samples, postlarvae, stomachs, and hepatopancreas of juvenile shrimp (Litopenaeus vannamei) using 389bp-PCR and 309bp-PCR for the detection of the infectious hypodermal and hematopoietic necrosis virus (IHHNV) in 15 farms of the Gulf of Nicoya and the Central Pacific of Costa Rica, during the 2017-2018 period.

\begin{tabular}{|c|c|c|c|c|c|c|c|c|}
\hline \multirow[b]{2}{*}{ Finca } & \multicolumn{8}{|c|}{ Tipo de muestra analizada mediante PCR } \\
\hline & Agua & Postlarvas & H1 & E1 & H2 & E2 & H3 & $\mathbf{E 3}$ \\
\hline 1 & + & - & $+^{*}$ & + & - & - & + & $+*$ \\
\hline 2 & + & - & - & + & - & + & + & + \\
\hline 3 & - & - & - & - & - & - & - & - \\
\hline 4 & + & + & + & $+*$ & - & $+*$ & - & + \\
\hline 5 & + & + & $+^{*}$ & - & $+^{*}$ & $t^{*}$ & - & + \\
\hline 6 & - & - & - & - & - & - & - & - \\
\hline 7 & - & - & + & + & + & + & - & - \\
\hline 8 & + & + & - & + & + & - & - & + \\
\hline 9 & - & + & - & + & + & $t^{*}$ & - & + \\
\hline 10 & + & + & + & + & + & + & + & + \\
\hline 11 & + & + & + & + & + & + & + & + \\
\hline 12 & - & + & - & - & - & - & - & + \\
\hline 13 & + & + & - & + & - & - & - & + \\
\hline 14 & + & + & - & - & - & - & - & - \\
\hline 15 & + & - & + & + & + & + & - & + \\
\hline
\end{tabular}

H1: hepatopáncreas de camarones recolectados en el sitio de la entrada de agua del estanque, E1: estómagos de camarones recolectados en el sitio de la entrada de agua del estanque, H2: hepatopáncreas de camarones recolectados en la mitad del estanque, E2: estómagos de camarones recolectados en la mitad del estanque, H3: hepatopáncreas de camarones recolectados en el extremo opuesto de la entrada del agua del estanque, E3: estómagos de camarones recolectados en el extremo opuesto de la entrada del agua del estanque. * $=$ Muestras positivas en el 389 pb-PCR y negativas en el 309 pb-PCR. / H1: shrimp hepatopancreas collected at the water entry site of the pond, E1: shrimp stomachs collected at the water entry site of the pond, H2: shrimp hepatopancreas collected in the middle of the pond, E2: shrimp stomachs collected in the middle of the pond, H3: shrimp hepatopancreas collected at the opposite site of water entry site of the pond, E3: shrimp stomachs collected at the opposite site of the water entry site of the pond. * = Positive samples in the $389 \mathrm{bp}-\mathrm{PCR}$ and negative in the $309 \mathrm{pb}-\mathrm{PCR}$.

La distribución de fincas positivas y negativas se muestra en la Figura 1. Se observa que las dos fincas negativas se encontraban situadas espacialmente muy distantes una de otra (finca 3 en la provincia de Guanacaste y finca 6 en la provincia de Puntarenas), sin embargo, se encontraban muy cerca de fincas que resultaron positivas a las muestras de agua, postlarvas y juveniles.

Las secuencias amplificadas con el 389 pb-PCR resultaron ser 99,2 \%-100,0 \% (386-389/389 pb) similares con la secuencia aislada en Litopenaeus vannamei de Venezuela (GenBank KM485615.1), con variaciones de uno a tres nucleótidos. Una de estas muestras, obtenida de agua, resultó 99,7 \% (388/389 pb) similar con una muestra de Venezuela, y 100 \% (388/389 pb) idéntica con otra proveniente de Texas, EEUU (MN968717.1), ambas de 




Figura 1. Distribución geográfica de las fincas productoras de camarón blanco (Litopenaeus vannamei), positivas y negativas al virus de la necrosis hipodérmica y hematopoyética infecciosa (IHHNV) en Costa Rica, durante el periodo 2017-2018 (Recuadros indican zonas ampliadas de fincas negativas).

Figure 1. Geographic distribution of positive and negative white shrimp (Litopenaeus vannamei) production farms to infectious hypodermal and hematopoietic necrosis virus (IHHNV) in Costa Rica, during the 2017-2018 period (Boxes indicate expanded areas of negative farms).

linaje III. La secuencia fue depositada en el GenBank, con el número de accesión MT270446. A su vez, las secuencias amplificadas con el 309 pb-PCR resultaron ser 98-100 \% (305-309/309 pb) similares a la de Venezuela (KM485615.1). Una de ellas fue depositada en GenBank (número de accesión MT163268), con 99 \% (242/244 pb) similaridad a la secuencia KM485615.1. El cladograma clasificó las secuencias dentro del linaje III del virus (Figura 2).

La encuesta evidenció un gran desconocimiento de los productores sobre el agente, ya que tan solo la mitad $(53,3 \%)$ de los productores conocían de IHHNV, mientras que un 46,6 \% sospechaba tener el agente en su finca. La presencia del agente se logró detectar en trece de las quince fincas analizadas, confirmando en todos los casos las sospechas de los productores (Cuadro 2). Solamente en las fincas 3 y 6, los productores no conocían, ni sospechaban de IHHNV. Estas fincas resultaron negativas al virus.

Solo una $(6,6 \%)$ de las quince fincas analizadas presentó parámetros fisicoquímicos óptimos, en lo que respecta a la calidad de agua, correspondiendo a una de las fincas IHHNV negativas del estudio. Los parámetros más alterados en los estanques fueron el oxígeno y la temperatura (Cuadro 3). 


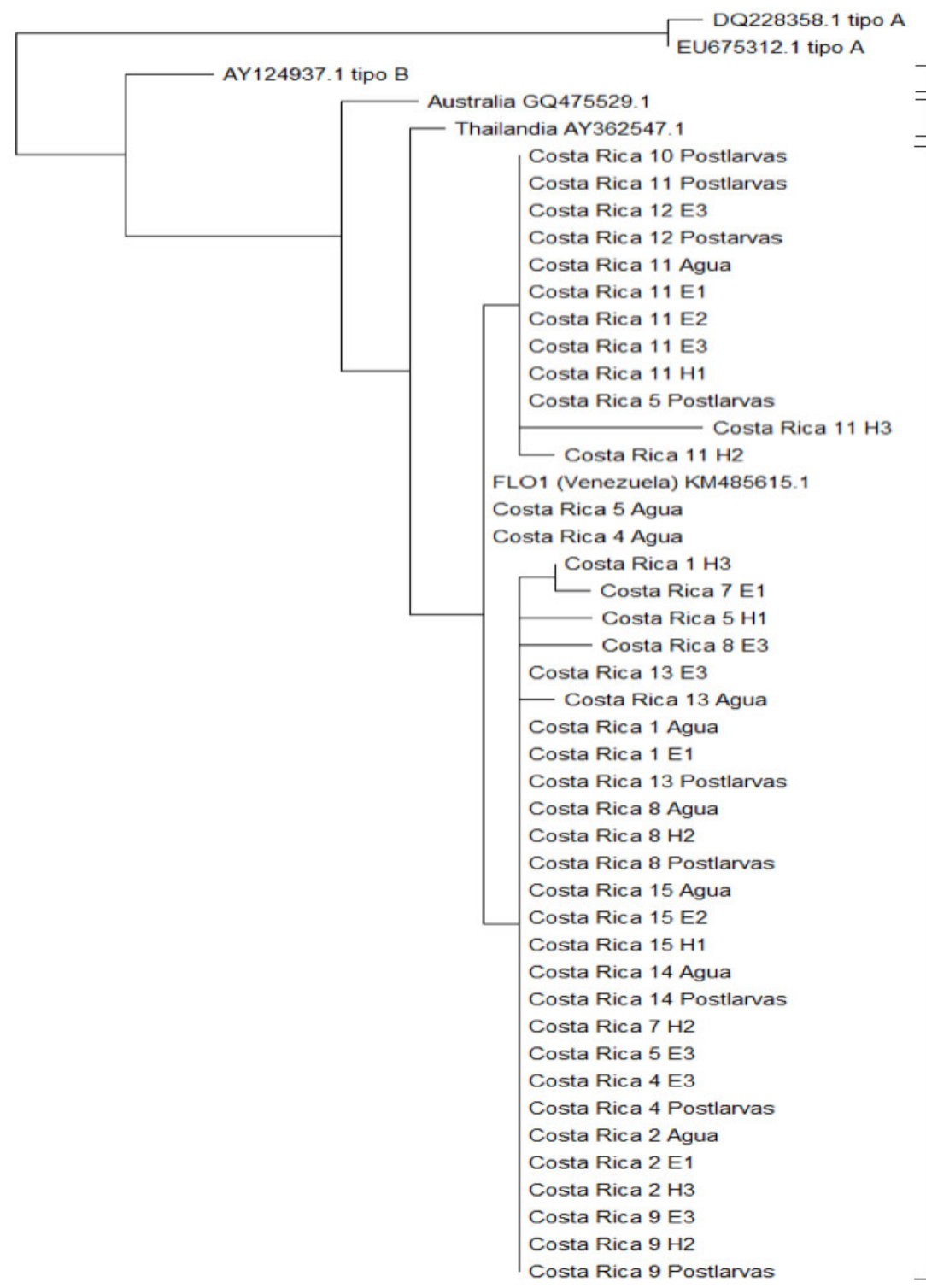

No patógenos

Linaje I

Linaje II

Linaje III

Figura 2. Cladograma de las secuencias amplificadas con el 389 pb-PCR para la detección del virus de la necrosis hipodérmica y hematopoyética infecciosa (IHHNV) en quince fincas productoras de camarón blanco (Litopenaeus vannamei), ubicadas en el Golfo de Nicoya, Costa Rica, durante el periodo 2017-2018.

Figure 2. Cladogram of the sequences amplified with the $389 \mathrm{bp}-\mathrm{PCR}$ for the detection of the infectious hypodermal and hematopoietic necrosis virus (IHHNV) in fifteen white shrimp (Litopenaeus vannamei) farms in the Gulf of Nicoya, Costa Rica, during the $2017-2018$ period. 
Cuadro 2. Conocimiento previo, presencia y estatus sanitario actual del virus de la necrosis hipodérmica y hematopoyética infecciosa (IHHNV) de quince fincas productoras de camarón blanco (Litopenaeus vannamei), ubicadas en el Golfo de Nicoya de Costa Rica, durante el periodo 2017-2018.

Table 2. Previous knowledge, presence, and current sanitary status of the infectious hypodermal and hematopoietic necrosis virus (IHHNV) of fifteen white shrimp (Litopenaeus vannamei) farms in the Gulf of Nicoya of Costa Rica, during the 2017-2018 period.

\begin{tabular}{cccc}
\hline Finca & $\begin{array}{c}\text { Conocimiento previo sobre } \\
\text { IHHNV }\end{array}$ & $\begin{array}{c}\text { Sospecha de la presencia de } \\
\text { IHHNV en la finca }\end{array}$ & $\begin{array}{c}\text { Estatus sanitario con respecto a } \\
\text { IHHNV en este estudio }\end{array}$ \\
\hline 1 & No & No & Positivo \\
2 & Sí & Sí & Positivo \\
3 & No & No & Negativo \\
4 & Sí & Sí & Positivo \\
5 & No & No & Negativo \\
6 & No & No & Positivo \\
7 & Sí & No & Positivo \\
8 & Sí & Sí & Positivo \\
9 & No & No & Positivo \\
10 & Sí & Sí & Positivo \\
11 & Sí & No & Positivo \\
12 & Sí & Sí & Positivo \\
14 & No & No & Positivo \\
& Sí & Sí & Positivo
\end{tabular}

Cuadro 3. Parámetros fisicoquímicos de la calidad del agua de quince fincas productoras de camarón blanco (Litopenaeus vannamei), ubicadas en el Golfo de Nicoya de Costa Rica, durante el periodo 2017-2018.

Table 3. Physicochemical parameters of the water quality of fifteen white shrimp (Litopenaeus vannamei) farms in the Gulf of Nicoya of Costa Rica, during the 2017-2018 period.

\begin{tabular}{ccccc}
\hline Finca & Oxígeno $\left(\mathbf{m g ~ l}^{-\mathbf{1}}\right)$ & Temperatura $\left({ }^{\circ} \mathbf{C}\right)$ & pH & Salinidad $(\mathbf{p p t})$ \\
\hline & $\geq 4,0^{*}$ & $27-30^{*}$ & $7,5-8,5^{*}$ & $75-30^{*}$ \\
1 & 2,28 & 31,25 & 7,72 & 28,81 \\
2 & 0,13 & 34,03 & 7,67 & 21,57 \\
3 & 0,60 & 33,17 & 7,75 & 22,01 \\
4 & 3,51 & 33,10 & 7,73 & 30,47 \\
5 & 3,00 & 34,53 & 8,24 & 22,39 \\
6 & 6,50 & 27,20 & 7,88 & 26,73 \\
7 & 3,80 & 29,38 & 6,75 & 37,82 \\
8 & 3,40 & 32,16 & 7,90 & 43,47 \\
9 & 5,13 & 32,17 & 7,65 & 29,12 \\
10 & 4,50 & 31,50 & 8,09 & 23,20 \\
11 & 2,96 & 31,16 & 7,54 & 25,44 \\
12 & 4,10 & 30,09 & 4,51 & 42,32 \\
13 & 4,60 & 31,46 & 7,90 & 26,80 \\
15 & 4,30 & 29,34 & 7,31 & 63,03 \\
\end{tabular}

*Valores óptimos / * Optimal Values. 


\section{Discusión}

Las dos pruebas moleculares utilizadas en el presente trabajo mostraron la misma especificidad. Sin embargo, el 389 pb-PCR determinó más casos positivos (mayor sensibilidad), por lo que se recomienda utilizar ese PCR en programas de vigilancia, tal y como lo recomienda también la Organización Mundial de Sanidad Animal (2019).

La prevalencia de IHHNV determinada a nivel de fincas $(86,7 \%)$, no concuerda con resultados obtenidos en países vecinos como Guatemala, Honduras, Belice, Nicaragua, México, Brasil y Venezuela, que reportaron prevalencias promedio de 13,4\% de IHHNV en L. vannamei (Morales-Covarrubias et al., 2011), ni tampoco con el único reporte de prevalencia de IHHNV en el país (Peña-Navarro \& Varela-Mejías, 2016). Se desconocen los factores que influyen para que países vecinos tengan prevalencias más bajas que Costa Rica, pero dentro de las posibles causas se podrían mencionar un mejor control sanitario (como por ejemplo utilizar semilla libre de patógenos), la aplicación de mejores prácticas de manejo (como mantener parámetros óptimos del agua, manejar densidades adecuadas de siembra, utilizar medidas de secado de estanque efectivas) o la aplicación de mayor bioseguridad en las fincas (por ejemplo evitando el ingreso de vectores al sistema) (Morales-Covarrubias et al., 2011). La distribución de fincas positivas y negativas sugiere que si bien existe un alto riesgo de diseminación del agente por contacto con agua contaminada de fincas vecinas, factores como manejo y bioseguridad en las fincas son más importantes para la presencia del agente en un sistema productivo (Glover et al., 1995).

Mediante la secuenciación se logró identificar por primera vez, secuencias asociadas al linaje III de IHHNV en Costa Rica, la cual se considera una cepa patógena para la especie L. vannamei (Silva et al., 2014). No se logró determinar la presencia de otros linajes (patógenos y no patógenos); sin embargo, debido a que se reporta que la infección por cepas no patógenas ocurre de manera natural en camarones silvestres, se recomienda analizar en futuras investigaciones la presencia de IHHNV en estos individuos. Se sugiere secuenciar el genoma completo de IHHNV (incluyendo los tres grandes marcos de lectura que conforman su genoma) para confirmar que las cepas aisladas en el estudio corresponden al linaje III de IHHNV (Nunan et al., 2000).

Las encuestas aplicadas a los productores evidenciaron que aproximadamente la mitad (53,3\%) desconocían de la existencia de IHHNV, mientras que otros, simplemente aceptaban la presencia del agente en la finca, como algo con lo que se debe de convivir, sin considerar el posible impacto económico que podría estar ocasionando en la finca (Lightner, 2003). Solamente una finca (6,6 \%) presentó parámetros físico-químicos óptimos del agua, mientras que las restantes mostraron alto nivel de oxígeno y temperatura, lo cual influye negativamente en la producción de camarones. El incremento en la temperatura implica un mayor consumo de oxígeno disuelto por parte de los camarones, ocasiona niveles bajos de oxígeno disuelto del mismo y desencadena un factor estresante en los camarones, que se refleja en disminución del consumo de alimento y muerte de los animales (Puente, 2009).

El presente estudio refleja la necesidad de colaboración de profesionales en forma multi- e interdisciplinaria con los productores de camarón. Esto con la finalidad de crear lineamientos para prevenir agentes infecciosos en las fincas, e incentivar a los productores a monitorear y mejorar los parámetros productivos de la finca, mediante estandarización de protocolos de bienestar, manejo y bioseguridad, permitiendo identificar los problemas y, de esta manera, tomar las medidas correctivas pertinentes (Food \& Drug Administration, 2018).

\section{Conclusión}

Se determinó la presencia del linaje patógeno III de IHHNV en la mayoría de las fincas, pero es importante confirmar estos hallazgos mediante secuenciación del genoma completo y determinar si IHHNV está provocando pérdidas económicas en estas fincas. 
El manejo inadecuado de los parámetros del agua del estanque podría ocasionar un impacto negativo en la salud de los animales y repercutir de manera directa en la baja productividad de los sistemas.

Se recomienda capacitar a los productores, así como incentivar el trabajo multi- e interdisciplinario, que involucre más médicos veterinarios que puedan apoyar junto al Servicio Nacional de Salud Animal el área clínica y la generación de programas de salud de estanque.

\section{Agradecimientos}

Los autores agradecen a los productores de las fincas camaroneras que aceptaron participar en esta investigación y a la Dra. Carolina Elizondo-Ovares del Departamento de Epidemiología, Programa Nacional de Sanidad Acuícola, Servicio Nacional de Salud Anima (SENASA), Costa Rica, por su apoyo incondicional. Este proyecto se financió mediante el Fondo Institucional de Desarrollo Académico (FIDA) de la Universidad Nacional (UNA) de Costa Rica en el marco del proyecto titulado "Situación sanitaria del camarón blanco (Litopenaeus vannamei) en zonas productivas de Costa Rica".

\section{Conflicto de Intereses}

Los autores declaran no tener ningún conflicto de intereses.

\section{Referencias}

Cowley, J. A., Rao, M., \& Coman, G. J. (2018). Real-time PCR tests to specifically detect IHHNV lineages and an IHHNV EVE integrated in the genome of Penaeus monodon. Diseases of aquatic organisms, 129(2), 145-158. https://doi. org/10.3354/dao03243

Cuéllar-Anjel, J. (2013). Necrosis infecciosa hipodérmica y hematopoyética (IHHNV). Center for Food Security and Public Health.http://www.cfsph.iastate.edu/Factsheets/es/infectious_hypodermal_and_hematopoietic_necrosis-es.pdf

Dhar, A. K., Roux, M. M., \& Klimpel, K. R. (2001). Detection and quantification of infectious hypodermal and hematopoietic necrosis virus and white spot virus in shrimp using real-time quantitative PCR and SYBR Green chemistry. Journal of Clinical Microbiology, 39(8), 2835-2845. https://doi.org/10.1128/JCM.39.8.2835-2845.2001

Food \& Drug Administration. (2018). Hazard analysis critical control point (HACCP). Retrieved September, 2018, from https:// www.fda.gov/food/guidance-regulation-food-and-dietary-supplements/hazard-analysis-critical-control-point-haccp

Felsenstein, J. (1985). Confidence limits on phylogenies: an approach using the bootstrap. Evolution; International Journal of Organic Evolution, 39(4), 783-791. https://doi.org/10.1111/j.1558-5646.1985.tb00420.x

Glover, K. L., Nunan, L. M., \& Lightner, D. V. (1995). Measurement using polymerase chain reaction (PCR) of the survival of infectious hypodermal and hematopoietic necrosis virus (IHHNV) subjected to shrimp culture disinfection techniques. In C. Browdy, \& S. Hopkins (Eds.), Swimming Through Troubled Water. Proceedings of the Special Session on Shrimp Farming (p. 239). World Aquaculture Society.

Hall, T. A. (1999). BioEdit: A user-friendly biological sequence alignment editor and analysis program for Windows 95/98/NT. Nucleic Acids Symposium Series, 41,95-98. https://doi.org/10.14601/Phytopathol_Mediterr-14998u1.29 
Kalagayan, H., Godin, D., Kanna, R., Hagino, G., Sweeney, J., Wyban, J., \& Brock, J. (1991). IHHN virus as an etiological factor in runt-deformity syndrome (RDS) of juvenile Penaeus vannamei cultured in Hawaii. Journal of the World Aquaculture Society, 22(4), 235-243. https://doi.org/10.1111/j.1749-7345.1991.tb00740.x

Kumar, S., Stecher, G., Li, M., Knyaz, C., \& Tamura, K. (2018). MEGA X: Molecular evolutionary genetics analysis across computing platforms. Molecular Biology and Evolution, 35(6), 1547-1549. https://doi.org/10.1093/molbev/msy096

Lightner, D. V. (2003). Exclusion of specific pathogens for disease prevention in a penaeid shrimp biosecurity program. In C. Lee, \& P. O’Bryen (Eds.), Biosecurity in aquaculture production systems. Exclusion of pathogens and other undesirables (pp. 81-116). World Aquaculture Society.

Montgomery-Brock, B. D., Tacon, A. G., Poulos, B., \& Lightner, D. V. (2007). Reduced replication of infectious hypodermal and hematopoietic necrosis virus (IHHNV) in Litopenaeus vannamei held in warm water. Aquaculture, 265(1-4), 4148. https://doi.org/10.1016/j.aquaculture.2007.01.025

Morales-Covarrubias, M., Ruiz-Luna, A., Moura-Lemus, A.P., Solís, V. T., \& Conroy, G. (2011). Prevalencia de enfermedades de camarón blanco (Litopenaeus vannamei) cultivado en ocho regiones de Latinoamérica. Revista científica FCVLUZ, 21(5), 434-446. https://www.redalyc.org/articulo.oa?id=95919362010

Nunan, L. M., Poulos, B. T., \& Lightner, D. V. (2000). Use of polymerase chain reaction for the detection of infectious hypodermal and hematopoietic necrosis virus in penaeid shrimp. Marine Biotechnology, 2, 319-328. https://doi. org/10.1007/s101260000003

Organización Mundial de Sanidad Animal. (2015). Manual de las pruebas de diagnóstico para los animales acuáticos. Recuperado en septiembre de 2017. http://www.oie.int/es/normas-internacionales/manual-acuatico/acceso-en-linea/

Organización Mundial de Sanidad Animal. (2017). Infection with infectious hypodermal and haematopoietic necrosis virus. Recuperado en setiembre 2017 de http://www.oie.int/es/normas-internacionales/manual-acuatico/acceso-en-linea/

Organización Mundial de Sanidad Anima. (2019). Infección por el virus de la necrosis hipodérmica y hematopoyética infecciosa. Recuperado en enero de 2019 de https://www.oie.int/index.php?id=2439\&L=2\&htmfile=chapitre_ihhn.htm

Peña-Navarro, N., \& Varela-Mejías, A. (2016). Prevalencia de las principales enfermedades infecciosas en el camarón blanco Penaeus vannamei cultivado en el Golfo de Nicoya, Costa Rica. Revista de Biología Marina y Oceanografía, 51(3), 553-564. https://dx.doi.org/10.4067/S0718-19572016000300007

Puente, E. (2009). Respuestas fisiológicas de juveniles de camarón blanco Litopenaeus vannamei, a condiciones oscilantes de oxígeno disuelto y temperatura [Tesis de Doctorado, Instituto Politécnico Nacional]. Repositorio del Instituto Politécnico Nacional. http://www.remeri.org.mx/portal/REMERI.jsp?id=oai:www.repositoriodigital.ipn.mx:123456789/14322

Robles-Sikisaka, R., Bohonak, A. J., McClenaghan, L. R., Jr, \& Dhar, A. K. (2010). Genetic signature of rapid IHHNV (infectious hypodermal and hematopoietic necrosis virus) expansion in wild Penaeus shrimp populations. PloS One, 5(7), Article e11799. https://doi.org/10.1371/journal.pone.0011799

Silva, D. C., Nunes, A. R., Teixeira, D. I., Lima, J. P., \& Lanza, D. C. (2014). Infectious hypodermal and hematopoietic necrosis virus from Brazil: Sequencing, comparative analysis and PCR detection. Virus Research, 189, 136-146. https://doi. org/10.1016/j.virusres.2014.05.008

Shike, H., Dhar, A. K., Burns, J. C., Shimizu, C., Jousset, F. X., Klimpel, K. R., \& Bergoin, M. (2000). Infectious hypodermal and hematopoietic necrosis virus of shrimp is related to mosquito brevidensoviruses. Virology, 277(1), $167-177$. https://doi.org/10.1006/viro.2000.0589 
Tang, K. F., \& Lightner, D. V. (2002). Low sequence variation among isolates of infectious hypodermal and hematopoietic necrosis virus (IHHNV) originating from Hawaii and the Americas. Diseases of Aquatic Organisms, 49(2), 93-97. https://doi.org/10.3354/dao049093

Tang, K. F., Navarro, S. A., \& Lightner, D. V. (2007). PCR assay for discriminating between infectious hypodermal and hematopoietic necrosis virus (IHHNV) and virus-related sequences in the genome of Penaeus monodon. Diseases of Aquatic Organisms, 74(2), 165-170. https://doi.org/10.3354/dao074165

Vanpatten, K. A., Nunan, L. M., \& Lightner, D. V. (2004). Seabirds as potential vectors of penaeid shrimp viruses and the development of a surrogate laboratory model utilizing domestic chickens. Aquaculture, 241(1-4), 31-46. https://doi. $\operatorname{org} / 10.1016 /$ j.aquaculture.2004.08.012 